\title{
Artigos
}

\section{Refletindo sobre a Educação Permanente em Saúde: potencialidades e limitações na terapia renal substitutiva}

\author{
Reflecting on permanent education for health: strengths and weaknesses in a \\ renal replacement therapy service (abstract: p. 18)
}

Reflejo de la educación permanente en salud: potencialidades y limitaciones en la terapia renal substitutiva (resumen: p. 18)

Ana Paula Freitas Lima ${ }^{(a)}$

Bárbara Souza Rocha(b)

<barbarasrocha@gmail.com>

Ida Helena Carvalho Fracescantonio Menezes( ${ }^{(c)}$

<idahelenamenezes@gmail.com>

Edna Regina Silva Pereira ${ }^{(d)}$

<ersp13@gmail.com> (a) Hospital das Clínicas, Universidade Federal de Goiás (UFG). Primeira Avenida, $s / n$ Setor Leste Universitário. Goiânia, GO, Brasil. 74605-020

(b) Faculdade de Enfermagem, UFG. Goiânia, GO, Brasil.

(c) Faculdade de Nutrição, UFG. Goiânia, GO, Brasil.

(d) Departamento de Clínica Médica, Faculdade de Medicina, UFG. Goiânia, GO, Brasil.

O objetivo deste estudo foi analisar as percepções e práticas dos profissionais da Saúde em Educação Permanente em Saúde (EPS) de uma unidade de terapia renal substitutiva. Trata-se de uma pesquisa de abordagem qualitativa com dados obtidos por meio de grupos focais com profissionais de nível superior de um hospital público federal de ensino que prestam assistência em um serviço de hemodiálise e diálise peritoneal, sendo os dados submetidos à análise de conteúdo, conforme descrito por Bardin. Os resultados demonstraram persistência de um modelo de educação na Saúde como recurso descontínuo de capacitação, centrado em categorias uniprofissionais, e a necessidade de institucionalização da EPS com o apoio da gestão. A execução da Metodologia da Problematização como eixo norteador propiciou aos participantes o desenvolvimento da noção de responsabilidade sobre o aprendizado e a possibilidade de mudança na realidade do serviço no qual estão inseridos.

Palavras-chave: Educação Permanente. Formação de recursos humanos. Terapia de substituição renal. 


\section{Introdução}

Desde a instituição da Política Nacional de Educação Permanente em Saúde (PNEPS), o processo de modificação da formação profissional busca articular e transformar as práticas e a educação na saúde; e organizar o trabalho, considerando a Educação Permanente (EP) como uma oportunidade de crescimento no ambiente laboral por meio de uma inversão na lógica anteriormente consolidada de Educação Continuada (EC) $)^{1,2}$. A Portaria n. 1.996, publicada em 2007 como reafirmação da PNEPS, definiu novas estratégias para a implementação da EP considerando as diretrizes operacionais dos pactos pela vida, de gestão e de controle social. Com a publicação dessa portaria, pretendeu-se contribuir para o desenvolvimento de açóes transformadoras com mudanças no enfoque educativo, incorporando o ensino e o aprendizado às práticas do trabalho no contexto em que ocorrem ${ }^{2,3}$.

Estudos identificaram uma evolução conceitual do termo "Educação Permanente em Saúde” (EPS), com incorporação dos princípios da educação problematizadora, realidade como contexto de ação e pedagogias não pautadas na transmissão, mas com pensamento crítico-reflexivo, embora relatem diversos desafios em relação a sua aplicação no contexto dos serviços, desarticulada da realidade e dos processos de trabalho vivenciados pelos profissionais ${ }^{4-6}$. Dessa forma, a EPS tem sido entendida como uma proposta indutora de mudanças por meio de uma aprendizagem significativa, mediada por metodologias ativas e problematização da realidade ${ }^{4}$.

Dentro dessa perspectiva da EP, recomenda-se um processo educativo embasado em ações que partirão de problemas reais, com uso de metodologias que permitem a formação de profissionais capazes de resolver ou até mesmo de revisar capacidades existentes que lhes inibem a resolução desses problemas ${ }^{7}$. Sendo assim, a PNEPS aponta a problematização como estratégia de trabalho, promovendo a discussão em equipe para reflexão das práticas².

A Metodologia da Problematização (MP) se caracteriza como uma metodologia de ensino, estudo e trabalho que pode ser utilizada para promover a mobilização dos educandos, por meio de um processo que envolve ação-reflexão sobre um aspecto da realidade observada, em situaçóes em que os temas estejam relacionados à vida em sociedade. Essa metodologia tem como base para a sua aplicação o Arco de Charles Maguerez, um caminho metodológico que orienta a prática pedagógica ${ }^{8,9}$.

Pautada nessas concepções, há de se destacar a Portaria n. 389, de 13 de março de 2014, que estabelece que os serviços de saúde integrantes da linha de cuidado à pessoa com doença renal crônica (DRC) deverão observar a garantia de EP de profissionais da Saúde para a prevenção, diagnóstico e tratamento da DRC e dos fatores de risco que levam a essa condição ${ }^{10}$.

Com uma elevação significativa nas suas taxas de incidência e prevalência, apresentando um aumento de 3\% de pacientes em terapia renal substitutiva (TRS) no Brasil no ano de $2017^{11}$, a DRC vem se apresentando como um problema grave de saúde pública, exigindo a atuação de uma equipe multiprofissional qualificada para a solução de problemas na perspectiva da EP. Diante dessas recomendaçôes e da complexidade do cotidiano das unidades de TRS, faz-se necessário estudos cujos resultados poderão indicar a relação da 
EPS com o desenvolvimento da prática rotineira das unidades de TRS, além de proposta de projetos de intervenção para o aprimoramento das equipes de trabalho e avaliação de informaçóes sobre mudanças na realidade.

Buscando compreender os desafios e as potencialidades da EPS e partindo da visão de que o uso de estratégias educacionais é um processo que depende dos contextos e da atuação dos atores envolvidos, este estudo teve seu desenvolvimento baseado na seguinte questão de pesquisa: Como os profissionais de um serviço de TRS percebem a EPS e como esta se desenvolve no cotidiano desse serviço? O objetivo foi analisar as percepçôes e práticas dos profissionais da Saúde em relação à EPS de uma unidade de TRS em um hospital público federal de ensino.

\section{Percurso metodológico}

Trata-se de um estudo descritivo-exploratório de abordagem qualitativa que permite a investigação de opiniôes e atitudes dos participantes levando em consideração aspectos que, dentro de um contexto específico, podem ser transformadores da realidade ${ }^{12}$. Este estudo seguiu o check-list do Consolidated Criteria for Reporting Qualitative Research (COREQ), que identifica critérios como forma de exploração de estudos qualitativos com descritores para cada item ${ }^{13}$.

A pesquisa foi desenvolvida entre os meses de setembro de 2017 e agosto de 2018, no estado de Goiás, em um hospital público federal de ensino referência no serviço de TRS composto por hemodiálise e diálise peritoneal. A população do estudo se constituiu por uma equipe assistencial de nível superior que desempenha suas funçôes nesse serviço, sendo composta por seis médico(a)s assistenciais, três médico(a)s residentes em Nefrologia, quatro enfermeiras, uma psicóloga, uma nutricionista e uma assistente social, totalizando 16 profissionais, que foram recrutados face a face para participar do presente estudo. Um total de nove profissionais aceitaram participar, demonstrando interesse e disponibilidade, e concordaram com a metodologia adotada no estudo, sendo excluídos aqueles que se encontraram afastados das atividades devido a férias e/ou licença médica no período de coleta de dados. Todos os profissionais convidados a participar receberam esclarecimentos sobre a pesquisa, e a coleta de dados somente se iniciou diante da aceitação destes e assinatura do Termo de Consentimento Livre e Esclarecido, elaborado pelas pesquisadoras.

A condução da pesquisa foi mediada pela pesquisadora principal, mestranda em ensino na Saúde e profissional do serviço, com apoio das demais pesquisadoras como facilitadoras, sendo todas doutoras e especialistas em Educação na Saúde pelo Foundation for Advancement of International Medical Education and Research (FAIMER ${ }^{\circledR}$ ) e uma com formação básica em dinâmica de grupo e em Coaching.

Como técnica de coleta de dados, foram utilizados dois grupos focais. Esse método é sugerido para a coleta de informaçóes por meio das respostas dos participantes às perguntas de investigação, que se dão na conversa entre os participantes mediados pelo moderador, podendo ser utilizado no entendimento de como se formam as diferentes percepçôes e atitudes acerca de um fato, prática ou serviços e das circunstâncias por meio das quais os significados foram construídos ${ }^{14,15}$. Para moderá-los, foram construídos 
previamente roteiros com questóes que estimulassem a reflexão coletiva. Foi escolhido na instituição uma sala apropriada para a realização da coleta de dados, a fim de facilitar a interação, evitando fatores que pudessem desviar a atenção ou interromper a discussão, na qual os participantes tiveram suas falas registradas em áudio utilizando-se gravador digital, que foram posteriormente transcritas para o processo de análise.

O primeiro grupo focal aconteceu antes da realização de uma ação de EPS, sendo apresentada a situação-problema que apontou a necessidade do estudo, e foi solicitado preenchimento de uma ficha de categorização profissional. Em seguida, foi utilizado um roteiro com perguntas sobre a existência de alguma atividade de EPS desenvolvida com os profissionais dentro da instituição; quais problemas do ambiente de trabalho os participantes consideravam importantes para serem abordados dentro de uma ação de EPS na TRS; o que eles acreditavam ser necessário para a organização e realização dessa ação; e a identificação de expectativas. A ação aconteceu no decorrer de três meses e foi desenvolvida em um total de quatro encontros presencias, totalizando oito horas de intervenção, com duração média de duas horas cada. A ação utilizou como estratégia os preceitos da $\mathrm{MP}^{9}$ e contou com a participação das pesquisadoras como facilitadoras, além da presença de uma pedagoga-membro do núcleo de EP da instituição.

O segundo grupo focal foi realizado após a implementação da intervenção, tendo como questóes norteadoras o cumprimento das expectativas apresentadas em relação à ação de EPS desenvolvidas nos encontros; a avaliação dos participantes em relação à ação de EPS e à experiência de utilização da MP; e o problema da unidade trabalhado pelo grupo. Os participantes foram ainda questionados sobre o aprendizado produzido, a oportunidade de aplicação ou mudança na prática e sugestóes para a melhoria das ações de EPS dentro do serviço de TRS.

Os dados foram submetidos à análise de conteúdo, na modalidade de análise temática, na qual o pesquisador busca categorizar os seguimentos que se repetem, inferindo uma expressão que os represente ${ }^{16}$. A utilização da análise de conteúdo conforme proposta por Bardin ${ }^{17}$ foi adotada, observando as etapas de preanálise, exploração do material e tratamento dos resultados, processo no qual as pesquisadoras procuraram torná-lo significativo e válido, estabelecendo relaçóes com a realidade.

Os participantes foram identificados por códigos, a fim de assegurar o sigilo de suas identidades, formados pela letra " $P$ " seguida de algarismos de 1 a 9 . Ressalta-se que a presente pesquisa foi desenvolvida seguindo os pressupostos éticos da Resolução n. $466 / 2012^{18}$ e só teve início após avaliação e aprovação do Comitê de Ética em Pesquisa da instituição, sob parecer n. 2.596.347. 


\section{Resultados e discussão}

\section{Categorização dos profissionais}

Participaram da pesquisa nove profissionais, que compuseram um grupo formado por três médico(a)s assistenciais, uma médica residente em Nefrologia, três enfermeiras, uma psicóloga e uma nutricionista. Vale ressaltar que a única categoria profissional de nível superior que compóe a equipe e que não participou do estudo foi o serviço social. Dos participantes dos grupos focais, oito eram do sexo feminino. Em relação à faixa etária, houve uma maior participação de profissionais com idade entre trinta e 39 anos (cinco), seguido de quarenta a 49 (três) e apenas uma pessoa com idade inferior a trinta anos. Os participantes do estudo atuavam, em média, há 11 anos na instituição. Em relação à formação desses profissionais, todos possuíam uma pós-graduação ou especialização, sendo quatro $(44,4 \%)$ mestres e um doutor.

\section{Categorização dos dados}

Da análise de conteúdo temática emergiram categorias e subcategorias com base nos objetivos e roteiros utilizados, bem como das falas apresentadas no material. As categorias "Capacitação ou Educação Permanente", "Problematização como eixo norteador" e "Assistência multiprofissional ao paciente em TRS” refletem questões que estiveram presentes nos discursos dos profissionais durante os grupos focais.

\section{Capacitação ou Educação Permanente}

Esta categoria foi composta por três subcategorias, a saber: "Insuficiências e inadequações", "Persistência do modelo tradicional" e "Fatores potencializadores e limitantes".

\section{Insuficiência e inadequações}

Ao eleger como objeto de reflexão a educação de profissionais inseridos no cotidiano dos serviços, entende-se a educação como parte indivisível do trabalho. Quando questionados sobre a existência de estratégias para a formação permanente em serviço na instituição, os participantes as percebem como insuficientes e com inadequaçôes, modelo esse reconhecido como não respondente aos princípios do Sistema Único de Saúde $(\mathrm{SUS})^{1}$. As falas se aproximam do conceito de EC como continuidade do modelo escolar, com ênfase na atualização de conhecimentos, aparecendo como recurso descontinuo de capacitação centrado em categorias uniprofissionais² ${ }^{2}$.

Existe, mas assim, é pouco, pelo que eu estou lembrando aqui para a área da Enfermagem foi só a SAE [Sistematização da Assistência de Enfermagem]. (P5) 
Existe curso de formação [...] teve aquele curso de cuidados paliativos [...] que está na terceira turma [...] é um curso de três meses, muito bom. (P8)

[...] recentemente na hemodiálise começou uma parte de educação permanente, com os funcionários, mas é para a Enfermagem. (P6)

$\mathrm{Na}$ Nutrição também a gente tem muito isso, mas é só da Nutrição [...]. (P9)

É uma coisa bem médica mesmo, porque assim é um [...] não só discussão de casos, mas também assim discussão do funcionamento da unidade, da questão organizacional, a teoria mesmo, não é uma coisa multiprofissional, é uma coisa segmentada. (P1)

As estratégias citadas se apresentam como pontuais, fragmentadas, uniprofissionais e desarticuladas, com foco em treinamentos, sem que haja uma reflexão sobre as necessidades do serviço e dos usuários. Esse resultado contraria a definição da EPS enquanto aprendizagem no trabalho com referência nas necessidades de saúde das pessoas e das populaçóes, da gestão setorial e do controle social ${ }^{1}$. Ora, Merhy ${ }^{19}$ afirma que os processos verdadeiramente comprometidos com a EP devem ter a capacidade de gerar no trabalhador, durante a produção de cuidado, transformaçôes da prática pela capacidade de problematizar a si mesmo no agir dentro do mundo do trabalho, sendo esse o grande desafio no plano individual e coletivo.

Após anos de publicação da PNEPS, a recomendação de espaços de discussão coletiva que permitam a formação de facilitadores, os serviços e os profissionais seguem com foco biomédico e ainda demonstram dificuldade em avançar na condução de estratégias que se configurem como EPS. Contradizendo essas recomendaçóes, os processos de capacitação e atualização presentes nos serviços mantém a lógica de transmissão de conhecimento específicos de cada profissão $0^{20,21}$. A concepção da PNEPS expressa relação com a incorporação do cotidiano às propostas formativas em saúde, porém, apesar da presença de publicaçóes recentes no intuito de apoiar o processo de planejamento de estratégias de EPS, as dificuldades permanecem.

Nesse contexto, a ausência de consenso sobre a educação no trabalho pode ser demonstrada pela existência de duas propostas distintas, sendo essas a EPS e a EC, que seguem presentes nos serviços de saúde, gerando confusão quando frequentemente tratados como sinônimos em relação à formação e qualificação no serviço, apesar de abordarem princípios metodológicos distintos ${ }^{22}$. 


\section{Persistência do modelo tradicional}

A prática educacional permanece centrada na figura do educador; sendo o seu papel historicamente direcionado para a transmissão do conhecimento. Apesar de reconhecer os movimentos para a formação de profissionais de saúde voltados para um cuidado integral, permanecem os desafios de atender e de ouvir as demandas do mundo do trabalho no qual estão inseridos ${ }^{23}$. Assim, a resistência à mudança e a persistência do modelo tradicional pautado na pedagogia da transmissão, a qual os profissionais foram expostos na sua formação, podem ser percebidas na descrição das atividades presentes neste estudo.

Exposição oral dialogada, porque faz uma exposição e a gente discute. (P7)

[...] a gente faz o treinamento então e também é só exposição, fica uma lá, falando, falando, falando até entrar na cabeça [...] mas aí quando a gente vai passar para o funcionário a gente trabalha de forma mais lúdica, a gente sempre inventa porque senão eles dormem [...] a gente faz muito isso para os funcionários, mas pra gente é sempre na forma mais tradicional do mundo. (P9)

Divergindo do processo de transferência do conhecimento, educar na perspectiva emancipatória permite a possibilidade de participação dos educandos na produção do saber, sendo a EPS pautada nessa concepção pedagógica ${ }^{24}$. Porém, igualmente, quando apresentadas as demandas dos profissionais para a estratégia de EP que estava sendo planejada, alguns profissionais apontaram a necessidade de desenvolvimento de atividades tradicionais para atualizar a equipe, resultado encontrado em outros estudos $^{25}$. As falas reforçam essa solicitação por uma educação tradicional, que se assemelha àquela que esses profissionais foram expostos durante sua formação, com procedimentos considerados já consolidados.

Eu acho que teria que ter uma aula sobre isso. (P7)

[...] seria importante a gente ter uma aula sobre essas portarias [...] uma aula explicativa, né, pra depois a gente poder elaborar de acordo, a gente trazer o que vamos utilizar no nosso contexto [...]. (P1)

Se um outro profissional vier com essa informação pra gente é melhor. (P9)

$\mathrm{O}$ ato de receber o conhecimento como se fosse um objeto é algo ainda muito presente nos discursos dos participantes, sendo que esse ato é representado pela figura do educador. Vale acrescentar que outros estudos realizados em hospitais evidenciam um perfil de ações educativas com temáticas assistenciais e de um processo de recuperação da saúde - sendo que profissionais demonstram desconhecer a base conceitual da EP em relação a esse processo - com tendência a reproduzir os modelos utilizados pelas instituiçốes ${ }^{26,27}$. 


\section{Fatores potencializadores e limitantes}

Como potencialidade da EPS nesse serviço de TRS, são percebidos pelos participantes os processos de formação que acontecem na instituição enquanto hospital-escola, a exemplo de estágios e residências, como contribuinte na formação da equipe. Esses depoimentos convergem na constituição da residência como espaço intercessor de mudanças designado à formação profissional, sendo as preceptorias apontadas como importantes atividades permeadas de $\mathrm{EP}^{28}$.

A gente tem o programa de aula com os residentes, que eu acredito que entraria [...] as atividades educativas que a gente faz com os residentes tem avaliação, a gente avalia presença, participação, pontualidade, é tipo um estágio que eles fazem na hemodiálise, contribui com a formação da equipe, né? (P1)

[...] os residentes da Nefrologia vão pra lá (hemodiálise) e dão aula, discutem com os preceptores. (P5)

Nós também acompanhamos os estudantes de Enfermagem da universidade que vêm e a gente também participa do processo de educação e avaliação dos alunos.

(P6)

Outrossim, a análise dos dados permitiu identificar fatores citados como intervenientes no processo de EPS, tais como desafios e limitações que emergiram no decorrer do estudo. Apesar de evidenciada uma disposição interna por parte dos profissionais, os mesmos referem que, sem o empenho e observância de sua importância pela gestão de forma institucionalizada, o desenvolvimento de ações de EPS fica limitado.

[...] eu acho realmente importante envolver a gerência [...]. (P1)

Eu acho que uma coisa é conscientizar a gerência dessa necessidade de educação permanente e buscar incentivar as equipes no hospital, eles têm essa formação ou informação, não sei, e incentivar isso de uma forma prática, assim, no hospital todo. Porque não adianta a gente ir por baixo, né, eu digo assim, lá do núcleo, né, começava a fomentar isso, né, e esbarrar em questóes de gestão [...]. (P8)

[...] não é só do serviço de Nefro, tem que ter essa conscientização geral do hospital. (P4)

Esse resultado vai ao encontro de outros estudos que apontam o apoio e sensibilização dos gestores como necessidade para a institucionalização da EPS; e que trazem que as propostas não podem ser construídas isoladamente, sendo fundamental a participação da gestão para a sua sustentabilidade enquanto estratégia de mudança ${ }^{29,30}$. 
Assim, podemos reforçar que a EPS como ferramenta que possibilita impactos na realidade deve ser do hospital enquanto estabelecimento de atenção à saúde, e não de um serviço em específico. Atendendo a essa premissa foi publicada, em agosto de 2018, uma portaria reestruturando o núcleo de EP na instituição pesquisada, com apresentação das suas principais atribuições e estratégias de atuação. Esse núcleo vem trabalhando no intuito de identificar profissionais da instituição que possam atuar como facilitadores nas atividades de EPS ligados às gerências administrativas, atenção à saúde e ensino/pesquisa, com a finalidade de descentralização e disseminação pedagógica das práticas de EP para o seu exercício no trabalho.

Tanto o desafio quanto a necessidade da continuidade das açóes foram citados pelos participantes, sendo inerentes à EPS e capazes de qualificar a assistência ${ }^{31}$, apontando como primordial o investimento constante no desenvolvimento de estratégias de EPS dentro da instituição.

\section{Problematização como eixo norteador}

Da segunda categoria, emergiram as seguintes subcategorias: "Metodologia de ensino e trabalho" e "Realidade como ponto de partida e chegada".

\section{Metodologia de ensino e trabalho}

A MP se utiliza de um esquema denominado Arco de Maguerez, que consiste em uma ferramenta didático-pedagógica que oferece uma oportunidade de aprendizado a partir da realidade vivida, levando em consideração a experiência e conhecimentos prévios dos educandos, percorrendo as etapas de observação da realidade, determinação de pontos-chave, teorização, hipóteses de solução e aplicação de determinado conhecimento à realidade ${ }^{32,33}$.

A escolha de uma estratégia utilizando a MP como eixo norteador pode propiciar aos profissionais o uso de variadas operaçóes, o desenvolvimento da autonomia do aprender e a possibilidade de mudança na realidade do serviço no qual estão inseridos. Estudos indicam que a MP favorece a reflexão crítica da realidade e da práxis, sendo percebidos avanços na sua utilização no que diz respeito à colaboração com a percepção da importância do comprometimento e da necessidade de transformação do cotidiano dos serviços de saúdét.

[...] sobre a questão da metodologia eu achei muito interessante da problematização, gostei muito do jeito que foi explicado, a questão daquele arco [de Maguerez], você colocar o problema, qual seriam as soluções, a gente discutia, então sem dúvida essa parte foi muito interessante. (P1) 
Assim, a questão da problematização ela consegue cada vez colocar um foco, né, por exemplo, sobre os nossos principais problemas, porque no início a gente abriu um monte de questóes e depois foi tentando fechar [...] a gente se perde porque são muitas questóes mesmo e aí acaba que às vezes você não sai do lugar [...] essa metodologia permitiu que a gente selecionasse um e fosse trabalhando e desenvolvendo em cima dele [...]. (P8)

Muito interessante e essa forma de problematização eu já conhecia, mas assim ela faz a gente participar do processo da construção, não traz algo pronto e aplica. (P7)

[...] conhecer a forma metodológica também eu acho que é um aprendizado de como trabalhar, porque igual a gente escuta falar, mas eu mesmo nunca tinha participado. (P5)

Ademais, vale ressaltar que a MP reconhece que a aprendizagem deve partir dos conhecimentos prévios do sujeito ${ }^{34}$, sendo esse fato ressaltado nos depoimentos dos participantes deste estudo.

Para construir, a gente tem que trazer o que conhece a respeito. (P8)

Eu penso que cada um trazer o que conhece a respeito ou o que pode informar. (P5)

Todos nós temos conhecimento, isso é facilitador, nós temos, né, agora põe na prática. (P6)

\section{Realidade como ponto de partida e chegada}

As recomendações são de que a formação dos trabalhadores do SUS não sejam mais definidas com base nas necessidades individuais de atualização, mas sim levando em consideração necessidades e problemas identificados nos cotidianos de atenção à saúde e de organização do trabalho ${ }^{30}$. Assim, a MP se diferencia de outras metodologias, sendo o seu ponto de partida e chegada a realidade a ser problematizada e extrapolando sua caracterização apenas como método pelo exercício intelectual e social a ela atribuído, que permite enxergar e transformar a realidade com maior criticidade, além de ser uma prática mais contextualizada, tão necessária à área da Saúde ${ }^{35}$.

Os participantes reconheceram a motivação em se reunir para tratar de problemas inerentes ao próprio processo de trabalho, resultado corroborado por outro estudo, no qual os entrevistados apontaram a importância da promoção de educação no trabalho voltada para sua realidade ${ }^{25}$. 
[...] gostei muito, trabalhar com problematização traz assim mais, a gente fica mais próximo da nossa realidade, né, então assim eu acho que aqui a gente fez um trabalho assim que realmente contemplou as minhas expectativas, que foi pra nossa realidade. $(\mathrm{P} 4)$

[...] um trabalho da problemática do serviço trabalhando com o grupo todas as pessoas que de uma forma ou de outra interferem no processo, assim é muito bom, eu acho que é uma tendência. (P6)

Nesses discursos, percebe-se a satisfação dos participantes em se reunir para trabalhar com a realidade, reconhecendo os problemas do cotidiano enquanto fundamento para o exercício da EPS, sendo esta fomentada por necessidades presentes em um serviço de saúde e realizada por meio de metodologias de ensino-aprendizagem que incluem a problematização dos processos e vivência do mundo do trabalho ${ }^{29}$. Miccas e Batista ${ }^{36}$, após analisarem outros estudos, perceberam como fundamental dentro do processo de formação permanente ações e decisões coletivas fundamentadas em práticas problematizadoras com aprendizagem deslocada para o ambiente de serviço.

\section{Assistência multiprofissional ao paciente em TRS}

Esta categoria emergiu da análise de conteúdo temática, das subcategorias modelo biomédico, do trabalho multiprofissional e das fragilidades nos recursos humanos.

\section{Modelo biomédico}

No cotidiano de trabalho de uma unidade de TRS, a disponibilidade da equipe multiprofissional para o estabelecimento de vínculos efetivos faz-se necessária em situaçóes de adoecimento crônico para desconstruir a assistência medicalizante que ainda persiste no ordenamento do processo de trabalho. Para os participantes, a assistência ao paciente nesse serviço de TRS ocorre de forma fragmentada, com o trabalho individualizado por área profissional, com práticas centradas em procedimentos. Mendonça e $\mathrm{Nunes}^{29}$ relatam que a persistência dessas práticas, além de representar um desafio, reforça a necessidade da implementação da política de EPS, pois o modelo vigente não responde aos desafios atuais da assistência pautada na integralidade.

[...] eu acho que é diferente o processo, não tem aquele momento multi(profissional), porque quando o médico chega, só o médico, e às vezes assim os pacientes ficam tão tristes porque eles não querem falar com você. (P9)

E assim porque tem o agendamento com o enfermeiro, que a gente tem agendamento de troca e extensão, nós temos muita coisa para olhar, tem atendimento com a psicóloga, com a Nutrição, isso tudo acontece, só que muitas vezes o paciente não dá valor a isso [...] se o staff passar mais cedo, eles não dão importância pros outros profissionais mesmo [...]. (P7) 
Mas à medida que você consegue criar vínculos com o paciente, ele quer ser atendido, mas a prioridade é o médico. (P5)

Ficou evidente no perfil delineado por essas falas da equipe multiprofissional que o modelo de assistência tradicional e biomédico, ainda é supervalorizado pelos usuários. Esse resultado corrobora com estudo de Oliveira e Wendhausen ${ }^{30}$, no qual vários trabalhadores referem em seus depoimentos uma população que reluta em aceitar uma nova perspectiva de atendimento executada pela equipe privilegiando consultas médicas. Contudo, os participantes deste estudo reconhecem nas falas a seguir a necessidade de valorização e acesso ao atendimento multiprofissional pela equipe para ser percebido como fundamental pelos pacientes.

Acho que tem que entender o paciente [...] ele tem que mudar essa cultura porque eles não conheciam o multidisciplinar, eles não tinham acesso a esse tipo de atendimento. (P6)

Nós precisamos nos organizar, descobrir nossas funções, porque o paciente não te adere porque ele não conhece o processo $[. .$.$] não conhece os profissionais em$ quem precisa passar [...]. (P7)

\section{O trabalho multiprofissional}

No conjunto das falas, há também a explicitação de que a troca de vivências e o compartilhamento nos encontros contribuíram para o vínculo enquanto equipe multiprofissional, sendo destacada a importância da troca efetiva para a qualificação $\mathrm{da}$ assistência. $\mathrm{O}$ apoio da equipe é reconhecido como importante, visto que a aprendizagem na EPS acontece, sobretudo com a inclusão dos profissionais em um processo coletivo de caráter transformador ${ }^{29,37}$.

A metodologia foi bem efetiva mesmo e assim a possibilidade de ter visóes diferentes, uma vez que é multiprofissional, eu acho isso importantíssimo, porque tá trazendo uma visão diferenciada de cada um dos problemas [...]. (P5)

Sinto muita falta dessa troca e essa técnica permitiu em outras situaçóes a gente discutir também o que era a preocupação (problemas) de cada um para o serviço, o que era possível, então assim é cada um trabalhando no seu espaço dificulta essa comunicação e interfere na assistência. (P8)

Para os participantes do estudo, esse espaço de discussão favoreceu a troca e o enfrentamento dos problemas desse serviço, resultado que corrobora com outros estudos que trazem a importância de criar mecanismos que estimulem a participação e o envolvimento de todos os profissionais da equipe ${ }^{29}$. 
(2)

Além disso, outra publicação apontou a tendência de os profissionais de saúde agirem isoladamente com promoção de cuidados pontuais em detrimento da assistência integral, o que não atende às necessidades dos usuários ${ }^{26}$. Outro estudo propóe um aprendizado transformador que valoriza a socialização e produção de profissionais da saúde, atores de mudanças com capacidade para tomada de decisão; o trabalho em equipe no sistema de saúde; e a adaptação dos recursos aos contextos locais, com estímulo ao abandono dos desenvolvimentos individuais em direção a alianças, integrando os sistemas educacionais e de saúde ${ }^{38}$.

\section{Fragilidades nos recursos humanos}

Foi frequente a afirmação de que diversas demandas e impasses consomem o tempo dos profissionais. Parte disso se deve ao fato de se tratar de um serviço de TRS inserido em um hospital de grande porte, atendendo inclusive urgências dialíticas e causando a sensação de absorção e sobrecarga de uma equipe reduzida.

[...] a gente tentar se organizar dentro do que for possível, tem questóes que esbarram na questão de funcionários, tem questões de horários, mas algumas acho que é possível a gente ir devagar movimentando, até para chegar e exigir isso em um patamar maior. (P8)

A questão dos entraves dos problemas é o mesmo, às vezes a gente vai com ideias ótimas de mudanças, tanto na hemodiálise quanto na diálise, mas sempre tem um entrave, primeiro porque a gente tá sempre só resolvendo as urgências e depois quando a gente vai pensar a gente chega a pensar nisso, não tem funcionários e esbarra de novo, vêm as urgências, esbarra de novo. (P7)

[...] pela sobrecarga de trabalho que a gente tem, pela demanda que é muito alta, e assim a gente sabe que tem que ter a intervenção, nós sabemos quais as intervençốes, mas a gente não tem pessoal [...]. (P5)

Diante dessas limitaçôes estruturais do cotidiano de trabalho, as falas dos participantes vão ao encontro de outro estudo no qual, apesar de abordar um cenário de prática distinto, a equipe também percebe a dificuldade de manter uma agenda de encontros de EPS e questiona a consistência do processo diante da descontinuidade das discussóes ${ }^{39}$. 


\section{Considerações finais}

A pesquisa mostrou que o potencial da EPS com a utilização de metodologias problematizadoras foi percebido pelos participantes no desenvolvimento de estratégias em busca da resolução de problemas voltados para as necessidades e realidade do serviço no qual estão inseridos.

No entanto, na unidade estudada, predominam atividades de educação com uma concepção tradicional de educação enquanto transmissão, não fornecendo subsídios para a reflexão sobre o cotidiano do trabalho. O estudo revela a manutenção de práticas pautadas na EC em detrimento da EPS como prática transformadora. Porém, faz-se necessário que as duas abordagens sejam vistas com um caráter complementar, sem se excluírem enquanto metodologias.

Observou-se também que as atividades educativas se destinam, predominantemente, aos trabalhadores por categorias profissionais com fragmentação das ações, visto que pouco se falou sobre atividades cujo público-alvo fosse a equipe de trabalho. Os discursos evidenciaram a necessidade de valorização profissional enquanto equipe multidisciplinar e o apoio da gestão no processo de implementação da EPS enquanto proposta de transformação. Foi possível perceber que discutir problemas e situações da realidade do serviço incentivou os participantes a refletirem sobre suas práticas e necessidade de participação em todo o processo educativo.

Este estudo, desenvolvido no contexto de um grande hospital universitário, apresenta como limitaçôes a realização em um único serviço de TRS inserido em uma unidade hospitalar com dificuldades relacionadas a horário e escala de trabalho dos participantes. Entendemos como necessários estudos que envolvam outros serviços que ofertem assistência a pacientes portadores de DRC em terapia dialítica, assim como, pesquisas sobre os impactos e efeitos que a EPS possa ter na qualidade da assistência aos usuários dentro dos serviços de saúde, vivências e concepçôes em outros cenários de prática. 


\section{Contribuição dos autores}

Todas as autoras participaram ativamente de todas as etapas de elaboração do manuscrito.

\section{Conflito de interesse}

As autoras não têm conflito de interesse a declarar.

\section{Direitos autorais}

Este artigo está licenciado sob a Licença Internacional Creative Commons 4.0, tipo BY (https://creativecommons.org/licenses/by/4.0/deed.pt_BR).

\section{(cc) BY}

\section{Editora}

Vera Lucia Garcia

Editor associado

Charles Tesser

\section{Submetido em}

$15 / 07 / 20$

Aprovado em

$21 / 01 / 21$

\section{Referências}

1. Brasil. Ministério da Saúde. Portaria n 198 GM/MS, de 13 de Fevereiro de 2004. Institui a Política Nacional de Educação Permanente em Saúde como estratégia do Sistema Único de Saúde para a formação e desenvolvimento de trabalhadores no setor. Brasília (DF): Ministério da Saúde; 2004.

2. Brasil. Ministério da Saúde. Política Nacional de Educação Permanente em Saúde. Brasília (DF): Ministério da Saúde; 2009.

3. Brasil. Ministério da Saúde. Portaria no 1.996, de 20 de Agosto de 2007. Dispóe sobre as diretrizes para a implementação da Política Nacional de Educação Permanente em Saúde. Brasília (DF): Ministério da Saúde; 2007.

4. Campos KFC, Sena RR, Silva KL. Educação permanente nos serviços de sáude. Esc Anna Nery. 2017; 21(4):1-10.

5. Rossetto M, Silva LAA. Acóes de educação permanente desenvolvidas para os agentes comunitários de saúde. Cogitare Enferm. 2010; 15(4):723-9.

6. Ricaldoni CAC, Sena RR. Educação Permanente: uma ferramenta para pensar e agir no trabalho de enfermagem. Rev Lat Am Enfermagem. 2006; 14(6):837-42. 
7. Farias PAM, Martin ALAR, Cristo CS. Aprendizagem ativa na educação em saúde: percurso histórico e aplicaçôes. Rev Bras Educ Med. 2015; 39(1):143-50.

8. Berbel NAN. A problematização e a aprendizagem baseada em problemas: diferentes termos ou diferentes caminhos? Interface (Botucatu). 1998; 2(2):139-54.

9. Berbel NAN. A metodologia da problematização em três versóes no contexto da didática e da formação de professores. Rev Dialogo Educ. 2012; 12(35):103-20.

10. Brasil. Ministério da Saúde. Portaria no 389, de 13 de Março de 2014. Define os critérios para a organização da linha de cuidado da pessoa com doença renal crônica e institui incentivo financeiro de custeio destinado ao cuidado ambulatorial prédialítico. Brasília (DF): ANVISA; 2014.

11. Thomé FS, Sesso RC, Lopes AA, Lugon JR, Martins CT. Inquérito brasileiro de diálise crônica 2017. J Bras Nefrol. 2019; 41(2):208-14.

12. Minayo MCS. O desafio do conhecimento: pesquisa qualitativa em saúde. 14a ed. São Paulo: Hucitec; 2014.

13. Tong A, Sainsbury P, Graig J. Consolidated criteria for reporting qualitative research (COREQ): a 32-item checklist for interviews and focus groups. Int J Qual Health Care. 2007; 19(6):349-57.

14. Escobar J, Bonilla-Jimenez FI. Grupos focales: una guía conceptual y metodológica. Cuad Hispanoam Psicol. 2009; 9(1):51-7.

15. Stalmeijer RE, McNaughton N, Van Mook WNKA. Using focus groups in medical education research: AMEE Guide No. 91. Med Teach. 2014; 36(11):923-39.

16. Caregnato RCA, Mutti R. Pesquisa qualitativa: análise de discurso versus análise de conteúdo. Texto Contexto Enferm. 2006; 15(4):679-84.

17. Bardin L. Análise de conteúdo. São Paulo: Edição 70; 2016.

18. Brasil. Ministério da Saúde. Conselho Nacional de Saúde. Resolução 466, 12 de Dezembro de 2012. Diretrizes e Normas Regulamentadora de Pesquisa Envolvendo Seres Humanos. Brasília (DF): Ministério da Saúde; 2012.

19. Merhy EE. O desafio que a educação permanente tem em si: a pedagogia da implicação. Interface (Botucatu). 2005; 9(16):172-4

20. Cunha AZS, Rezende MS, Weigelt LD, Krug BF, Feil AI. Implicações da educação permanente no processo de trabalho em saúde. Rev Esp Saude. 2014; 15(4):64-75.

21. Macêdo NB, Albuquerque PC, Medeiros KR. O desafio da implementação da educação permanente na gestão da educação na saúde. Trab Educ Saude. 2014; $12(2): 379-401$.

22. Montanha D, Peduzzi M. Educação permanente em enfermagem: levantamento de necessidades e resultados esperados segundo a concepção dos trabalhadores. Rev Esc Enferm USP. 2010; 44(3):597-604.

23. Mourthé Junior CA, Lima VV, Padilha RQ. Integrando emoções e racionalidades para o desenvolvimento de competência nas metodologias ativas de aprendizagem. Interface (Botucatu). 2018; 22(65):577-88.

24. Ceccim RB. Educação permanente em saúde: desafio ambicioso e necessário. Interface (Botucatu). 2005; 9(16):161-77.

25. Silva JAM, Peduzzi M. Educação no trabalho na atenção primária à saúde: interfaces entre a educação permanente em saúde e o agir comunicativo. Saude Soc. 2011; 20(4):1018-32. 
26. Tronchin DMR, Mira VL, Peduzzi M, Ciampone MHT, Melleiro MM, Silva JAM, et al. Educação permanente de profissionais de saúde em instituiçóes públicas hospitalares. Rev Esc Enferm USP. 2009; 43(Esp 2):1210-5.

27. Koerich C, Erdmann AL. Significados atribuídos pela equipe de enfermagem sobre educação permanente em uma instituição cardiovascular. Rev Rene. 2016; 17(1):93-102.

28. Silva CT, Terra MG, Kruse MHL, Camponogara S, Xavier MS. Residência multiprofissional como espaço intercessor para a educação permanente em saúde. Texto Contexto Enferm. 2016; 25(1):1-9.

29. Mendonça FF, Nunes EFPA. Necessidades e dificuldades de tutores e facilitadores para implementar a política de educação permanente em saúde em um município de grande porte no estado do Paraná, Brasil. Interface (Botucatu). 2011; 15(38):871-82.

30. Oliveira SRG, Wendhausen ALP. (Re)significando a educação em saúde: dificuldades e possibilidades da Estratégia Saúde da Família. Trab Educ Saude. 2014; 12(1):129-46.

31. Mishima SM, Aiub AC, Rigato AFG, Fortuna CM, Matumoto S, Ogata MN, et al. Perspectiva dos gestores de uma regiáo do estado de São Paulo sobre eucação permanente em saúde. Rev Esc Enferm USP. 2015; 49(4):659-67.

32. Berbel NAN, Gamboa SAS. A metodologia da problematização com o Arco de Maguerez: uma perspectiva teórica e epistemológica. Filos Educ. 2012; 3(2):264-87.

33. Vieira MNCM, Panúncio-Pinto MP. A Metodologia da Problematização (MP) como estratégia de integração ensino-serviço em cursos de graduação na área da saúde. Medicina (Ribeirão Preto). 2015; 48(3):241-8.

34. Bergamim MD, Prado C. Problematização do trabalho em equipe em enfermagem: relato de experiência. Rev Bras Enferm. 2013; 66(1):134-7.

35. Colombo AA, Berbel NAN. A metodologia da problematização com o Arco de Maguerez e sua relação com os saberes de professores. Semin Cienc Soc Hum. 2007; 28(2):121-46.

36. Miccas FL, Batista SHSS. Educação permanente em saúde: metassíntese. Rev Saude Publica. 2014; 48(1):170-85.

37. Mancia JR, Cabral LC, Koerich MS. Educação permanente no contexto da enfermagem e na saúde. Rev Bras Enferm. 2004; 57(5):605-10.

38. Frenk J, Chen L, Bhutta ZA, Cohen J, Crisp N, Evans T, et al. Health professionals for a new century: transforming education to strengthen health systems in an interdependent world. Lancet. 2010; 376(9756):1923-58.

39. Silva DLS, Knobloch F. A equipe enquanto lugar de formação: a educação permanente em um Centro de Atenção Psicossocial Álcool e outras drogas. Interface (Botucatu). 2016; 20(57):325-35. 
This study analyzes the perceptions and practices of health professionals undergoing permanent education for health in a renal replacement therapy center. We conducted a qualitative study using data collected during focus group discussions with health professionals with a degree working in a hemodialysis and peritoneal dialysis service in a public teaching hospital. The data were analyzed using the content analysis method described by Bardin. The findings shows that the model of education based on discontinuous training centered on single professional groups prevails. There is a need to institutionalize permanent education for health with the support of managers. The use of the problematization method as a guiding framework enabled participants to develop a notion of responsibility in relation to learning and the potential to change the reality of the service in which they work.

Keywords: Permanent education. Human resource training. Renal replacement therapy.

El objetivo de este estudio fue analizar las percepciones y prácticas de los profesionales de la salud en la Educación Permanente en Salud (EPS) de una unidad de terapia renal substitutiva. Investigación de abordaje cualitativo, con datos obtenidos por medio de grupos focales con profesionales de nivel superior, de un hospital público federal de enseñanza, que dan asistencia en un servicio de hemodiálisis y diálisis peritoneal, sometiéndose los datos a análisis de contenido, conforme descrito por Bardin. Los resultados demostraron la persistencia de un modelo de educación en salud como recurso discontinuo de capacitación, centrado en categorías uniprofesionales y la necesidad de institucionalización de la EPS con el apoyo de la gestión. La ejecución de la Metodología de la Problematización como eje regidor propició a los participantes el desarrollo de la noción de responsabilidad sobre el aprendizaje y la posibilidad de cambio en la realidad del servicio en el que estamos inseridos.

Palabras clave: Educación permanente. Formación de recursos humanos. Terapia de substitución renal. 